\title{
Natural resolution of non-anaphylactic shrimp allergy in patients diagnosed 10 years earlier by oral food challenge
}

\author{
Suttipong Ittiporn, ${ }^{1}$ Surapon Piboonpocanun, ${ }^{2}$ Punchama Pacharn, ${ }^{1}$ Nualanong Visitsunthorn, ${ }^{1}$ \\ Torpong Thongngarm, ${ }^{3}$ Orathai Jirapongsananuruk ${ }^{1}$
}

\begin{abstract}
Background: Shrimp allergy is considered a lifelong condition. The natural resolution of shrimp allergy is not well studied.

Objective: To investigate the natural resolution of shrimp allergy among a cohort of patients diagnosed with shrimp allergy 10 years earlier by oral shrimp challenge.

Methods: A prospective study recruited patients diagnosed with shrimp allergy to Penaeus monodon (Pm), Macrobrachium rosenbergii $(\mathrm{Mr})$, or both from a study conducted during 2005-2006. The current oral shrimp challenges were conducted during 2015-2016. The negative oral shrimp challenge was designated 'resolved shrimp allergy' (RSA), with a positive challenge designated 'persistent shrimp allergy' (PSA). Skin prick and prick-to-prick testing to shrimp were used to determine sensitization.
\end{abstract}

Results: Sixty patients who had positive shrimp challenge from the previous cohort were contacted. Patients who had previous anaphylactic reaction (8 subjects) or allergic reaction after shrimp ingestion within 6 months (6 subjects), were not included. Nine patients refused to participate and 20 patients could not be contacted. Seventeen patients were included. Three were previously diagnosed with allergy to $\mathrm{Pm}, 3$ to $\mathrm{Mr}$, and 11 to both species. RSA was observed in 1 patient with isolated $P m$ allergy, and in 3 patients with isolated $M r$ allergy. Three of 9 patients with dual allergy had RSA to both species. RSA patients had significantly smaller size of shrimp skin test than PSA patients at both diagnosis and follow-up.

Conclusions: At ten years after diagnosis, $46 \%$ of patients had RSA. These patients had significantly smaller size of shrimp skin test than PSA patients.

Key words: allergy, food allergy, natural resolution, oral food challenge, shrimp, tolerance

\footnotetext{
Affiliations:

${ }^{1}$ Division of Allergy and Clinical Immunology,

Department of Pediatrics, Faculty of Medicine Siriraj Hospital, Mahidol University, Bangkok, Thailand

${ }^{2}$ Institute of Molecular Biosciences, Mahidol University, Salaya Campus, Nakhon Pathom, Thailand

Division of Allergy and Clinical Immunology,

Department of Medicine, Faculty of Medicine Siriraj Hospital,

Mahidol University, Bangkok, Thailand
}

Corresponding author:

Orathai Jirapongsananuruk

Division of Allergy and Clinical Immunology,

Department of Pediatrics

Faculty of Medicine Siriraj Hospital, Mahidol University

2 Wanglang Road, Bangkoknoi, Bangkok 10700, Thailand

E-mail: orathai.pib@mahidol.ac.th; jirapongo@yahoo.com

\section{Introduction}

The prevalence of food allergy was $8 \%$ and $5 \%$ in children adults, respectively. ${ }^{1}$ This prevalence was increasing over the past 10-15 years, especially among infants and preschool children. ${ }^{1}$ Common food allergens in infants and young children in Asia are milk, eggs and wheat with the prevalence of 0.83 $5 \%, 3-4 \%$ and $0.08 \%$ respectively. Adults are more allergic to shellfish, fish and peanut with the prevalence of $7.05 \%, 1.17 \%$ and $0.48 \%$ respectively. ${ }^{1-4}$

Shellfish, especially shrimp, was a leading cause of food allergy among adolescents and adults. ${ }^{3,5-8}$ In Asia, shellfish allergy was more common than peanut allergy which was in contrast to those in Western countries. ${ }^{79}$ A study from Singapore reported that sensitization to shellfish (77\%) was higher than peanut $(45 \%)$ among children greater than 4 years of age. ${ }^{10}$ 
Moreover, shellfish was the leading cause of food-induced anaphylaxis, especially in Asian countries. ${ }^{7,8,11,12}$

At least 2 studies reported allergy to specific shrimp species in a subset of shrimp allergic patients. ${ }^{13,14}$ During 20052006, we studied 68 children who had history of shrimp allergy and positive skin tests to shrimp. Using oral food challenges (OFC) to Penaeus monodon (Pm; saltwater shrimp) and Macrobrachium rosenbergii ( $\mathrm{Mr}$; freshwater shrimp), we identified specific allergy to $\mathrm{Pm}$ and $\mathrm{Mr}$ in $17.65 \%$ and $23.53 \%$ of children, respectively. Positive and negative OFC to both shrimp species was found in $47.06 \%$ and $11.76 \%$ of children, respectively. ${ }^{13}$ A study from Singapore also confirmed species-specific shrimp allergy in adults who had positive OFC to $P m$ and Litopenaeus vannamei $(L v) .{ }^{14}$ Shrimp allergens such as tropomyosin, arginine kinase, myosin light chain and sarcoplasmic calcium binding protein are well characterized in $\mathrm{Pm}$ and $L v{ }^{15}$ The protein antigens in $M r$ were not widely studied since this shrimp is not available worldwide. Our group has characterized the cross-reactive tropomyosin and non-cross reactive hemocyanin in $M r .^{16,17}$

Unlike egg, wheat, soy, and cow's milk, peanut and shellfish allergy are regarded as lifelong allergies. ${ }^{5,18,19}$ However, Ho, et al., followed children less than 2 years of age who had wheal size from skin prick test (SPT) to peanut $\geq 95 \%$ of positive predictive value (PPV) for up to 8 years. Peanut challenges were performed when SPT responses decreased to less than 95\% PPV. They found that $21 \%$ of children with peanut allergy developed clinical tolerance by 5 years of age. ${ }^{20}$ In addition, recent data from the HealthNuts study revealed that $22 \%$ of infants with challenge-proven peanut allergy developed peanut tolerance by 4 years of age. ${ }^{21}$

Despite the findings that natural resolution of peanut allergy can occur, the natural course of shrimp allergy has not been well studied. The aim of this study was to investigate the natural resolution of shrimp allergy among a cohort of patients who were diagnosed as having non-anaphylactic shrimp allergy 10 years earlier by OFC, and to identify factors associated with shrimp tolerance.

\section{Methods \\ Subjects}

This prospective cohort included patients who were diagnosed with shrimp allergy to $\mathrm{Pm}, \mathrm{Mr}$, or both from a study that we conducted during 2005-2006. ${ }^{13}$ The current study was conducted during 2015-2016. Both studies were conducted at the Division of Allergy and Clinical Immunology, Department of Pediatrics, Siriraj Hospital. This study was approved by the Siriraj Institutional Review Board (SIRB), (COA no. 017/2559, EC1). Written informed consent was obtained from all participants.

Due to the ethical concern, patients who had previous anaphylactic reaction to shrimp or recent allergic reaction after shrimp ingestion within the past 6 months, were not included. Patients with underlying diseases such as cardiovascular, hepatobiliary, and renal diseases; severe systemic infection; and/or pregnancy, were excluded. Patients with allergic diseases, such as asthma, allergic rhinitis, urticaria, and atopic dermatitis, were stable for more than 7 days before OFC.
Peak expiratory flow rate was more than $70 \%$ of predicted value on the day of OFC. None of the patients were on $\beta$-blocking agents or systemic corticosteroid.

In our previous study, 68 children with a history of shrimp allergy and skin tests positive to shrimp were orally challenged with $\mathrm{Pm}$ and $\mathrm{Mr} .{ }^{13}$ We found 12 patients who had allergy to $\mathrm{Pm}$ only, 16 patients to $\mathrm{Mr}$ only, and 32 patients to both shrimp species. Patients who had anaphylaxis, and 8 patients who had negative OFC to shrimp were excluded from the current study. The remaining 52 patients met the inclusion criteria and were invited to participate in this study. The flow of participants throughout the study is shown in Figure 1.

\section{Skin test procedure}

Skin tests were performed using the previously described method. ${ }^{13}$ In brief, SPT using $P m$ and $M r$ extracts (PmSPT and $M r S P T$ ), and prick-to-prick (PTP, pricking the food and then pricking the skin of the patients) method using cooked $\mathrm{Pm}$ and $\mathrm{Mr}$ (PmPTP and MrPTP) were performed. The P. monodon and $M$. rosenbergii extracts were freshly prepared by making a dilution of 1:10 (wt/volume) of raw lyophilized shrimp in Coca's solution. The sensitivity and specificity for PmSPT, PmPTP MrSPT and MrPTP were $97.73 \%$ and $8.33 \%$, $100 \%$ and $4.17 \%, 97.92 \%$ and $5 \%, 100 \%$ and $0 \%$, respectively. ${ }^{13}$ The glycerinated saline and histamine phosphate $10 \mathrm{mg} /$ $\mathrm{mL}$ were negative and positive controls, respectively. Antihistamines were discontinued for at least 7 days prior to skin testing. The mean of the largest and midpoint orthogonal diameters of wheals was recorded as the mean wheal diameter (MWD), and was considered positive if it was $3 \mathrm{~mm}$ larger than the negative control.

\section{Oral food challenge procedure}

OFC to $\mathrm{Pm}$ and/or $\mathrm{Mr}$ was performed in patients identified in our previous study as having allergy to $\mathrm{Pm}$, to $\mathrm{Mr}$, or to both shrimp species. ${ }^{13}$ The open OFC protocol was modified from our and previous reports. ${ }^{13,22-24}$ The protocol comprised challenges in three steps, with multiple doses in two of the steps. Steps were performed 15 minutes apart. The provocation dose (PD) in the first step consisted of raw lyophilized shrimp in capsules which were given as follows: $500 \mathrm{mg}, 1,2$, and $4 \mathrm{~g}$ given at 15-minute intervals. The cumulative PD was $7.5 \mathrm{~g}$. The second step was to identify oral-mucosal reactions by swabbing $2 \mathrm{~g}$ of cooked shrimp onto the inner lips, placing it into the mouth without chewing for 5 minutes, and then removed. Lip itching/swelling and/or throat itching was recorded as a positive oral-mucosal reaction. The third step involved open feeding of cooked shrimp. The PD schedule of cooked shrimp was, as follows: 1, 2, 4, and $8 \mathrm{~g}$ at 15-minute intervals. The cumulative PD was $15 \mathrm{~g}$. A positive response to one or more steps of the OFC was considered a positive challenge. Patients who had a positive reaction to both shrimp species were challenged 2-4 weeks later with other shrimp species. If the patient had no reaction to the OFC, a telephone follow-up was conducted 2-3 weeks later to inquire if the patient had any reaction to shrimp consumption. Anaphylaxis was diagnosed according to established criteria. ${ }^{25}$ Patient symptoms and signs were recorded every 15 minutes during OFC. 


\section{Outcomes of shrimp OFC}

Negative shrimp challenge was designated 'resolved shrimp allergy' (RSA), with a positive challenge designated 'persistent shrimp allergy' (PSA). The outcome of this study was categorized into 3 outcomes as the following:

Outcome 0: Patients had positive OFC to $\mathrm{Pm}$ only, $\mathrm{Mr}$ only, or both species in our previous report, ${ }^{13}$ but, had negative shrimp OFC in the current study.

Outcome 1: Patients had positive OFC to $\mathrm{Pm}$ only or $\mathrm{Mr}$ only in our previous study, and still had positive OFC in the current study. Patients who had allergy to both shrimp species in the previous report ${ }^{13}$ tolerated one shrimp species in the current study.

Outcome 2: Patients had positive OFC to both shrimp species in both the previous and current study.

\section{Statistical analysis}

Data are presented as mean \pm standard deviation or median and range for continuous data, and as number and percentage for categorical data. Pearson's chi-square test and Fisher's exact test were used to analyze categorical data. Comparisons between parameters of RSA and PSA groups were done using independent T-test or Mann-Whitney $U$ test if the data were not normally distributed. A $p$-value $\leq 0.05$ was considered significant.

\section{Results \\ Subjects}

Of the 52 patients who met the inclusion criteria, 6 had allergic reaction to shrimp ingestion within the past 6 months, 9 refused to participate and 20 could not be contacted. The remaining 17 patients were recruited. Three patients had isolated allergy to $P m, 3$ had isolated allergy to $M r$, and 11 had allergic reaction to both shrimp species (Figure1, Tables $\mathbf{1}$ ).

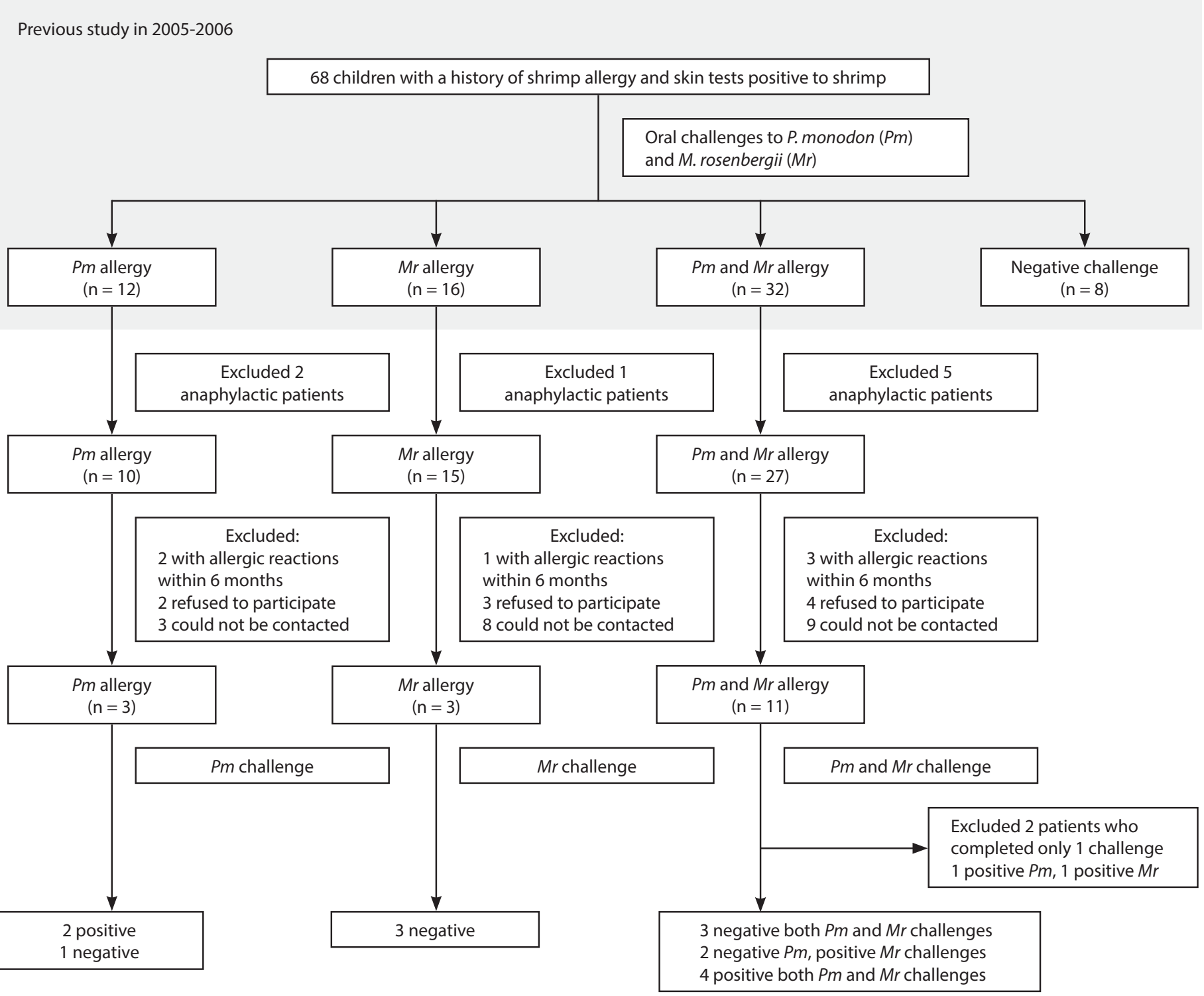

Figure 1. The flowchart of participants throughout the study and outcome of shrimp challenges. The area in grey zone represents the results from previous study.

Abbreviations: $M r, M$. rosenbergii; $P m, P$. monodon 


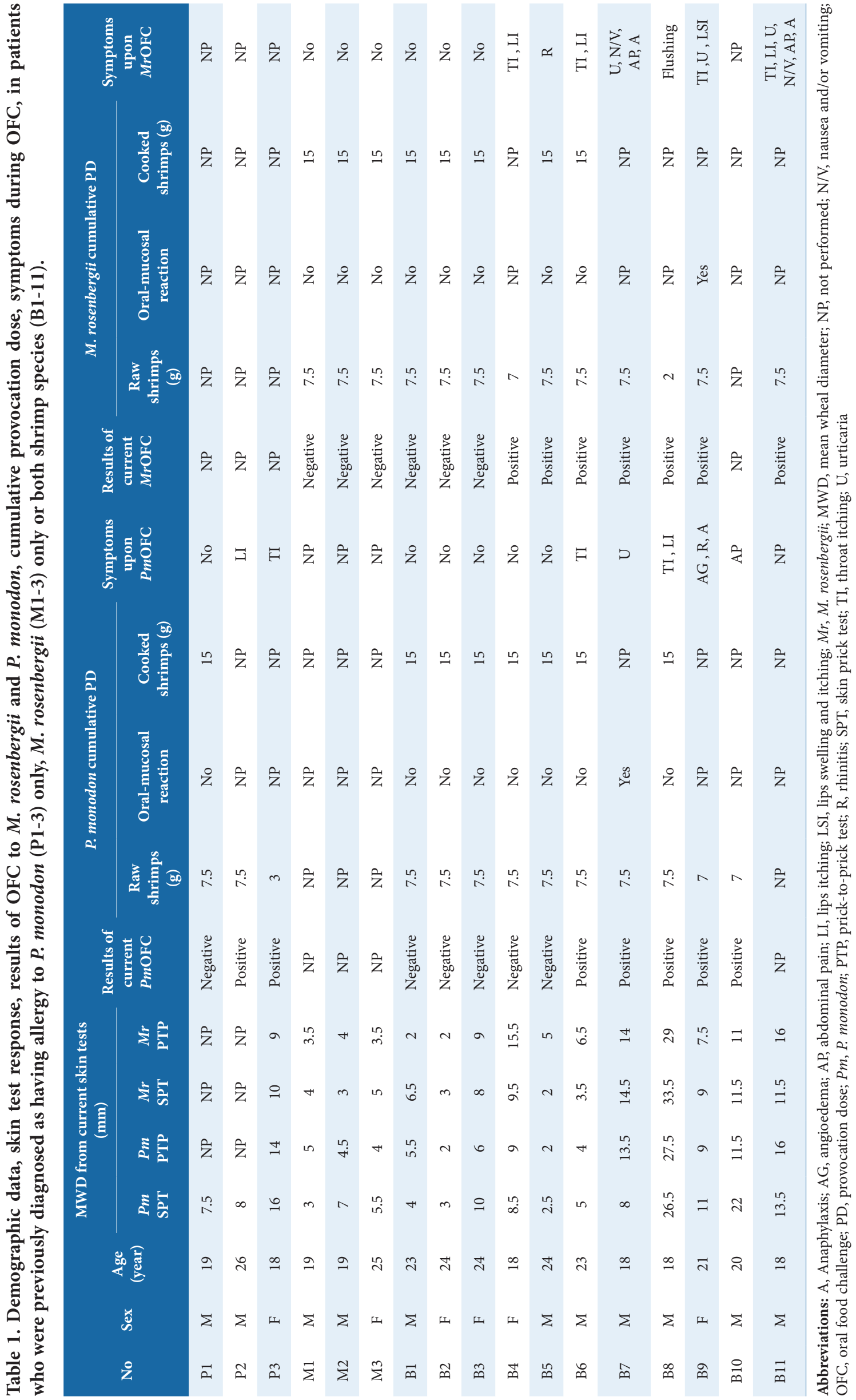


Demographic data, personal and family history of atopy, other food allergy besides shrimp, route of exposure, symptoms and onset of shrimp allergy in the past, are shown in Table 2. Underlying allergic diseases, such as asthma, allergic rhinitis, and atopic dermatitis, were found in $76.5 \%$ of patients. Allergic reaction to other food, such as crab, mollusks, or fish, was found in $82.4 \%$ of patients.

\section{Results of shrimp OFC}

In this study, 1 of the 3 patients (patient's number P1 in Table 1) who were previously diagnosed as having isolated allergy to $\mathrm{Pm}$ had negative challenges to $\mathrm{Pm}$ (Figure 1, Table 1). All of the patients (M1-M3) who were previously diagnosed as having isolated allergy to $\mathrm{Mr}$ had negative challenges to $M r$ (Figure 1, Table 1).

\section{Table 2. Patient characteristics and outcomes of oral food challenges to shrimp}

\begin{tabular}{|c|c|c|c|c|c|}
\hline Characteristics & $\begin{array}{l}\text { No. of patients } \\
\begin{array}{c}(\mathrm{N}=17)(100 \%) \\
n(\%)\end{array}\end{array}$ & $\begin{array}{c}\text { Outcome 0 } \\
(\mathbf{N =} 7)(46.6 \%) \\
\text { n }(\%)\end{array}$ & $\begin{array}{c}\text { Outcome } 1 \\
\begin{array}{c}(\mathrm{N}=4)(26.7 \%) \\
\text { n }(\%)\end{array}\end{array}$ & $\begin{array}{c}\text { Outcome } 2 \\
(\mathrm{~N}=4)(26.7 \%) \\
\text { n }(\%)\end{array}$ & $p$ value \\
\hline Male gender & $10(58.8 \%)$ & $4(57.1 \%)$ & $2(50.0 \%)$ & $2(50.0 \%)$ & 1.00 \\
\hline Type of shrimp allergy & & & & & 0.17 \\
\hline - Penaeus monodon (Pm) & $3(17.6 \%)$ & $1(14.2 \%)$ & $2(50.0 \%)$ & $0(0.0 \%)$ & \\
\hline - Macrobrachium rosenbergii $(\mathrm{Mr})$ & $3(17.6 \%)$ & $3(42.9 \%)$ & $0(0.0 \%)$ & $0(0.0 \%)$ & \\
\hline - Both $P m$ and $M r$ & $11(64.8 \%)$ & $3(42.9 \%)$ & $2(50.0 \%)$ & $4(100 \%)$ & \\
\hline Current age (years), mean \pm SD & $21.1 \pm 2.9$ & $22.3 \pm 2.7$ & $22.1 \pm 4.0$ & $20.8 \pm 2.5$ & 0.71 \\
\hline Patient history of atopic diseases & & & & & 0.75 \\
\hline - No & $4(23.5 \%)$ & $1(14.3 \%)$ & $1(25.0 \%)$ & $2(50.0 \%)$ & \\
\hline - Yes & $13(76.5 \%)$ & $6(85.7 \%)$ & $3(75.0 \%)$ & $2(50.0 \%)$ & \\
\hline Family history of atopic diseases & & & & & 1.00 \\
\hline - No & $11(64.7 \%)$ & $4(57.1 \%)$ & $3(75.0 \%)$ & $2(50.0 \%)$ & \\
\hline - Yes & $6(35.3 \%)$ & $3(42.9 \%)$ & $1(25.0 \%)$ & $2(50.0 \%)$ & \\
\hline Food allergies other than shrimp & & & & & 0.20 \\
\hline - No & $3(17.6 \%)$ & $0(0.0 \%)$ & $2(50.0 \%)$ & $1(25.0 \%)$ & \\
\hline - Yes & $14(82.4 \%)$ & $7(100 \%)$ & $2(50.0 \%)$ & $3(75.0 \%)$ & \\
\hline \multicolumn{6}{|l|}{ Route of exposure to $\mathrm{Pm}$ or $\mathrm{Mr}$} \\
\hline - Oral & $17(100 \%)$ & $7(100 \%)$ & $4(100 \%)$ & $4(100 \%)$ & NA \\
\hline - Touch or vapor inhalation & $8(47.1 \%)$ & $2(28.6 \%)$ & $2(50.0 \%)$ & $2(50.0 \%)$ & 0.66 \\
\hline \multicolumn{6}{|l|}{ Symptoms from the previous shrimp challenge } \\
\hline - Skin and soft tissue & $16(94.1 \%)$ & $7(100 \%)$ & $3(75.0 \%)$ & $4(100 \%)$ & 0.53 \\
\hline - Upper respiratory tract & $5(29.4 \%)$ & $2(28.6 \%)$ & $1(25.0 \%)$ & $1(25.0 \%)$ & 1.00 \\
\hline - Gastrointestinal tract & $1(5.9 \%)$ & $0(0.0 \%)$ & $1(25.0 \%)$ & $0(0.0 \%)$ & 0.53 \\
\hline Onset of reaction after ingestion of $P m$ or $M r$ & & & & & 0.75 \\
\hline$-<30$ minutes & $13(76.5 \%)$ & $5(71.4 \%)$ & $3(75.0 \%)$ & $4(100 \%)$ & \\
\hline$-\geq 30$ minutes & $4(23.5 \%)$ & $2(28.6 \%)$ & $1(25.0 \%)$ & $0(0.0 \%)$ & \\
\hline Route of birth & & & & & 1.00 \\
\hline - Normal labor & $7(41.2 \%)$ & $3(42.9 \%)$ & $2(50.0 \%)$ & $2(50.0 \%)$ & \\
\hline - Cesarean section & $10(58.8 \%)$ & $4(57.1 \%)$ & $2(50.0 \%)$ & $2(50.0 \%)$ & \\
\hline Duration of breastfeeding (months) & & & & & 0.81 \\
\hline$-<4$ months & $10(58.8 \%)$ & $5(71.4 \%)$ & $3(75.0 \%)$ & $2(50.0 \%)$ & \\
\hline - $\geq 4$ months & $7(41.2 \%)$ & $2(28.6 \%)$ & $1(25.0 \%)$ & $2(50.0 \%)$ & \\
\hline
\end{tabular}


APJAI

Table 2. Patient characteristics and outcomes of oral food challenges to shrimp

\begin{tabular}{|c|c|c|c|c|c|}
\hline Characteristics & $\begin{array}{l}\text { No. of patients } \\
\begin{array}{c}(\mathrm{N}=17)(100 \%) \\
n(\%)\end{array}\end{array}$ & $\begin{array}{c}\text { Outcome 0 } \\
(\mathrm{N}=7)(46.6 \%) \\
\text { n (\%) }\end{array}$ & $\begin{array}{c}\text { Outcome 1 } \\
(\mathrm{N}=4)(26.7 \%) \\
\mathrm{n}(\%)\end{array}$ & $\begin{array}{c}\text { Outcome 2 } \\
(\mathrm{N}=4)(26.7 \%) \\
\mathrm{n}(\%)\end{array}$ & $p$ value \\
\hline Number of siblings & & & & & 1.00 \\
\hline$-<2$ & $15(88.2 \%)$ & $6(85.7 \%)$ & $3(75.0 \%)$ & $4(100 \%)$ & \\
\hline$-\geq 2$ & $2(11.8 \%)$ & $1(14.3 \%)$ & $1(25.0 \%)$ & $0(0.0 \%)$ & \\
\hline Complete avoidance of $\mathrm{Pm}$ or $\mathrm{Mr}$ & & & & & 0.06 \\
\hline - No & $6(35.3 \%)$ & $5(71.4 \%)$ & $1(25.0 \%)$ & $0(0.0 \%)$ & \\
\hline - Yes & $11(64.7 \%)$ & $2(28.6 \%)$ & $3(75.0 \%)$ & $4(100 \%)$ & \\
\hline
\end{tabular}

Comparisons between outcomes were done using independent T-test or Mann-Whitney $U$ test if the data were not normally distributed.

Abbreviations: $M r, M$. rosenbergii; Pm, P. monodon; SD, standard deviation; NA, not available

A

50.0

40.0

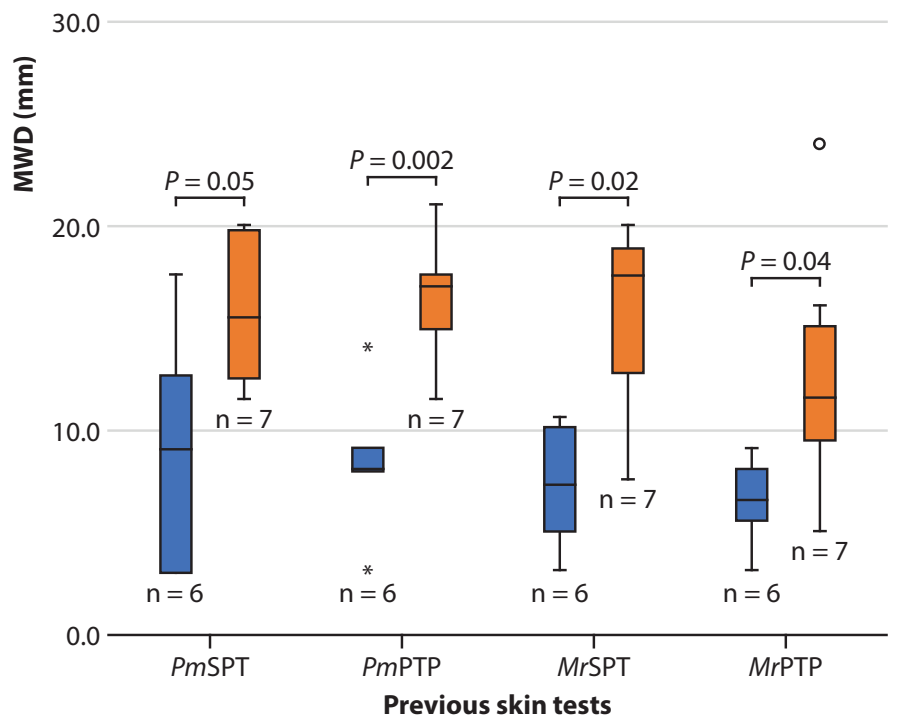

RSA
B 40.0

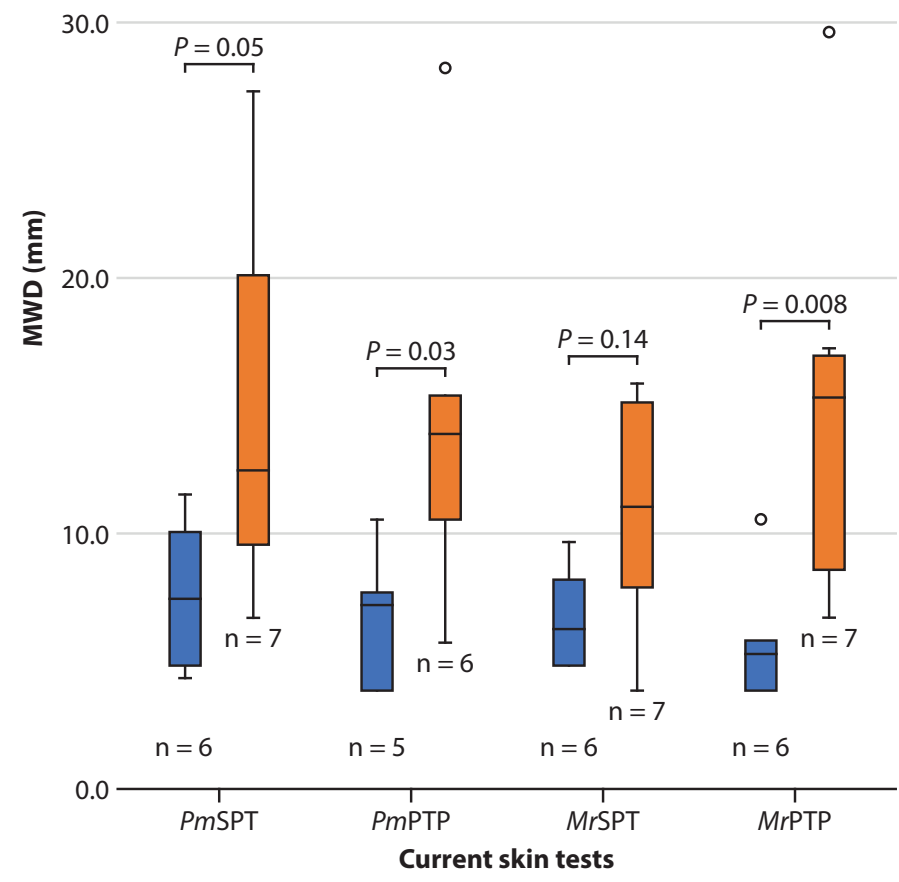

Figure. 2. Comparisons of the mean wheal diameter (MWD) of skin tests in patients with 'resolved (RSA)' or 'persistent shrimp allergy (PSA)' from previous (A) and current (B) studies. The numbers under the bars represent number of subjects. Comparisons between groups were done using Mann-Whitney $U$-test.

Abbreviations: $M r, M$. rosenbergii; MWD, mean wheal diameters; Pm, P. monodon; PTP, prick-to-prick tests; SPT, skin prick tests. 
Eleven patients who were allergic to both shrimp species were scheduled for re-challenge to both shrimp species. However, 2 patients $(\mathrm{B} 10, \mathrm{~B} 11)$ refused to participate in the $2^{\text {nd }}$ challenge after having an allergic reaction to the $1^{\text {st }}$ challenge (Figure 1, Table 1). Therefore, in this group of dual allergy, 10 challenges to $\mathrm{Pm}$ and 10 to $\mathrm{Mr}$ were done. Of the 9 patients who had complete OFC to both shrimp species, 3 patients had negative challenges to both species (B1-B3). Two patients had negative challenges to $\mathrm{Pm}$ but positive challenges to $\mathrm{Mr}$ (B4-B5). Four patients had positive challenges to both $\mathrm{Pm}$ and $\mathrm{Mr}$ (B6-B9).

Therefore, RSA was found in $1 / 3$ of the patients who were previously allergic to $P m$, and in $3 / 3$ of the patients who were previously allergic to $M r$. In patients who were previously allergic to both $\mathrm{Pm}$ and $\mathrm{Mr}$, RSA to both shrimp species was found in $3 / 9$ patients.

Overall, there were 26 challenges. Six of 13 (46\%) challenges to $P m$ and 6/13 (46\%) challenges to $M r$, were negative. The mean onset of allergic reactions after OFC was 7.50 (range 1-120) minutes. The most common allergic reactions were found on the skin and soft tissue (85.7\%), followed by gastrointestinal (21.4\%) and respiratory system (14.3\%). Anaphylaxis was found in 3 patients who were previously allergic to both shrimp species.

Fifteen patients who completed the challenge protocol, were divided into 3 outcome categories since some patients with dual shrimp allergy had RSA to one shrimp species but PSA to another species. Seven (46.6\%) patients (P1, M1-M3, B1-B3 in Table 1) had RSA, and were designated as having 'Outcome 0'. Four (26.7\%) patients (P2-P3, B4-B5 in Table 1) had PSA to one shrimp species, and were designated as having 'Outcome 1'. Four (26.7\%) patients (B6-B9 in Table 1) had PSA to both shrimp species, and were designated as having 'Outcome 2'. Factors investigated for the association with these outcomes are listed in Table 2. No factors were found to significantly associate with RSA. The age at diagnosis of shrimp allergy was not a significant predictor of outcome (data not shown).

A telephone follow-up was conducted to inquire if patients with negative challenge developed any allergic reaction upon shrimp consumption. Those follow-up calls revealed no allergic reactions in patients with negative OFC in the current study.

\section{Results of skin tests}

The results of PmSPT, PmPTP, MrSPT, and MrPTP from included patients are shown in Table 1 . These skin test results were compared with the results from the previous study in the same patients. ${ }^{13}$ The median MWD of PmSPT in the previous and current studies was 12.5 (range 3.0-35.0) $\mathrm{mm}$ and 8.0 (range $2.5-26.5) \mathrm{mm}$, respectively $(p=0.11)$. The median PmPTP in the previous and current studies was 14.0 (range $3.0-21.0) \mathrm{mm}$ and 9.0 (range $2.0-27.5) \mathrm{mm}$, respectively $(p=$ 0.20 ). The median MWD of MrSPT in the previous and current studies was 10.0 (range 3.0-45.0) $\mathrm{mm}$ and 6.5 (range 2.0$33.5) \mathrm{mm}$, respectively $(p=0.02)$. The median $M r \mathrm{PTP}$ in the previous and current studies was 8.5 (range 3.0-24.0) $\mathrm{mm}$ and 6.5 (range $2.0-29.0) \mathrm{mm}$, respectively ( $p=0.53$ ).
The data of skin tests from our previous study ${ }^{13}$ in the same patients included in the current study are shown in Figure 2A. The median MWD for PmSPT, PmPTP, MrSPT and MrPTP in patients with RSA were significantly smaller than those in patients with PSA. In the current study, median MWD for PmSPT, PmPTP, MrPTP in patients with RSA were significantly smaller than those in patients with PSA. However, median MWD of MrSPT was not significantly different between RSA and PSA groups. (Figure 2B).

In patients with $\mathrm{Pm}$ allergy, the PmSPT MWD decreased $18.0 \%$ (range: $-233.3-80.0 \%$ ) from the data obtained from the previous study in the RSA group, and decreased 29.0\% (range: $-91.3-63.0 \%)$ in the PSA group $(p=0.95)$. The PmPTP MWD decreased $57.1 \%$ (range: $-83.3-75.0 \%$ ) from the previous study in the RSA group, and decreased $20.5 \%$ (range: -61.8-81.0\%) in the PSA group ( $p=0.79$ ). In patients with $M r$ allergy, the MrSPT MWD decreased 30.0\% (range: -116.7-71.4\%) from the previous study in the RSA group, and decreased $45.7 \%$ (range: $-53.3-90.0 \%)$ in the PSA group $(p=0.95)$. The MrPTP MWD decreased $37.4 \%$ (range: $-12.5-69.2 \%$ ) from the previous study in the RSA group, but increased 20.8\% (range: -52.4-69.2) in the PSA group $(p=0.10)$.

\section{Discussion}

Understanding the natural history of shrimp allergy helps physicians to determine whether or not and when rechallenge of shrimp is appropriate. Shrimp allergy has long been considered lifelong, and patients have generally been instructed to strictly avoid shrimp.

Daul, et al. investigated the natural history of shrimp hypersensitivity and found that 7 of 11 shrimp hypersensitive patients had positive shrimp challenges. ${ }^{26}$ The shrimp-specific $\operatorname{lgE}$ (sIgE) of all subjects were stable during the 24-month period and the authors concluded that shrimp hypersensitivity was a persistent condition. In contrast, Ayuso, et al. studied IgE-binding to specific epitopes of 4 shrimp allergens in children and adults with immediate allergic reactions to shrimp. ${ }^{27}$ Children with shrimp allergy had higher shrimp sIgE, and more intense IgE binding to all shrimp peptides and to more diverse epitopes than adults. These findings suggest a decline in sIgE and the possible waning of shrimp allergy overtime.

The current study followed patients with shrimp allergy 10 years earlier, and re-challenged them to shrimp. We identified RSA in 7/15 (46\%) patients who previously had allergy to either $\mathrm{Pm}, \mathrm{Mr}$, or both shrimp species. To our knowledge, this is the first study to demonstrate the resolution of shrimp allergy by performing follow-up challenges in patients who had challenge-proven shrimp allergy.

Skin test size in the current study showed a declining trend compared to the same patients in our previous report. ${ }^{13}$ However the decrease was only statistically significant for $\mathrm{Mr}$ SPT. This finding is in support of Ayuso, et al., who suggested that IgE sensitivity to shrimp decreases over time. ${ }^{27}$

Factors other than specific food antigens that predict persistent food allergy have been reported. ${ }^{28}$ These factors include more severe symptoms upon antigen ingestion, lower $\mathrm{PD}$, presence of allergic comorbidities, adult onset, greater SPT MWD, higher food sIgE, and persistent SPT reactivity 
or food sIgE over time. ${ }^{1,19-21,28-33} \mathrm{Ho}$, et al. reported that $21 \%$ of children with peanut allergy became tolerant by the age of 5 years. Skin prick test to peanut more than $6 \mathrm{~mm}$ before the age of 2 years was a predictor of persistent peanut allergy. ${ }^{20}$ Peters, et al. found that $22 \%$ of children with peanut allergy developed tolerance by the age of 4 years. Skin prick test to peanut at 1 and 4 years of age predicted resolved or persistent peanut allergy at 4 years of age. ${ }^{21}$ Our present study found smaller skin test sizes in patients with RSA compared to patients with PSA (except for MrSPT) in both the current study and the study we conducted 10 years ago.

The strength of this study is a long-term study and the RSA is proven by OFC. This study has some mentionable limitations. A number of patients were either lost to follow-up or refused to participate since most of them were in adult ages and changed their addresses or would not want to miss their works. Patients with anaphylaxis or recent allergic reaction to shrimp were excluded since they were not allowed to participate by the ethic committee. In general, these patients were not considered shrimp challenge in the real allergy practices.

In conclusion, $46 \%$ of shrimp allergic patients had RSA at ten years after diagnosis. Moreover, RSA patients had significantly smaller MWD than PSA patients at both diagnosis and at the ten-year follow-up.

\section{Acknowledgements}

The authors gratefully thank Miss Julaporn Pooliam from the Division of Clinical Epidemiology, Department of Research and Development, Faculty of Medicine Siriraj Hospital for statistical analysis, and Chaweewan Sripramong, BSc. and Sunisa Aulla, BSc. for technical support.

\section{Potential conflicts of interest}

The authors have no conflicts of interest relevant to this article to disclose.

\section{Financial support}

This study was supported by a Siriraj Grant for Research Development from the Faculty of Medicine Siriraj Hospital, Mahidol University, Bangkok, Thailand (grant number (IO) R015933017).

\section{References}

1. Sicherer SH, Sampson HA. Food allergy: Epidemiology, pathogenesis, diagnosis, and treatment. J Allergy Clin Immunol. 2014;133:291-307; quiz 8.

2. Moore LE, Stewart PH, deShazo RD. Food Allergy: What We Know Now. Am J Med Sci. 2017;353:353-66.

3. Santadusit S, Atthapaisalsarudee S, Vichyanond P. Prevalence of adverse food reactions and food allergy among Thai children. J Med Assoc Thai. 2005;88 Suppl 8:S27-32.

4. Lee AJ, Thalayasingam M, Lee BW. Food allergy in Asia: how does it compare? Asia Pac Allergy. 2013;3:3-14.

5. Sicherer SH, Munoz-Furlong A, Sampson HA. Prevalence of seafood allergy in the United States determined by a random telephone survey. J Allergy Clin Immunol. 2004;114:159-65.

6. Ben-Shoshan M, Harrington DW, Soller L, Fragapane J, Joseph L, St Pierre $\mathrm{Y}$, et al. A population-based study on peanut, tree nut, fish, shellfish, and sesame allergy prevalence in Canada. J Allergy Clin Immunol. 2010;125: 1327-35.
7. Lopata AL, O'Hehir RE, Lehrer SB. Shellfish allergy. Clin Exp Allergy. 2010;40:850-8.

8. Turner P, Ng I, Kemp A, Campbell D. Seafood allergy in children: a descriptive study. Ann Allergy Asthma Immunol. 2011;106:494-501.

9. Shek LP, Cabrera-Morales EA, Soh SE, Gerez I, Ng PZ, Yi FC, et al. A population-based questionnaire survey on the prevalence of peanut, tree nut, and shellfish allergy in 2 Asian populations. J Allergy Clin Immunol. 2010;126:324-31, 31 e1-7.

10. Chiang WC, Kidon MI, Liew WK, Goh A, Tang JP, Chay OM. The changing face of food hypersensitivity in an Asian community. Clin Exp Allergy. 2007;37:1055-61.

11. Jirapongsananuruk $O$, Bunsawansong W, Piyaphanee N, Visitsunthorn N, Thongngarm T, Vichyanond P. Features of patients with anaphylaxis admitted to a university hospital. Ann Allergy Asthma Immunol. 2007; 98:157-62.

12. Ganapathy S, Lwin Z, Ting DH, Goh LS, Chong SL. Anaphylaxis in Children: Experience of 485 Episodes in 1,272,482 Patient Attendances at a Tertiary Paediatric Emergency Department from 2007 to 2014. Ann Acad Med Singapore. 2016;45:542-8

13. Jirapongsananuruk O, Sripramong C, Pacharn P, Udompunturak S, Chinratanapisit S, Piboonpocanun S, et al. Specific allergy to Penaeus monodon (seawater shrimp) or Macrobrachium rosenbergii (freshwater shrimp) in shrimp-allergic children. Clin Exp Allergy. 2008;38:1038-47.

14. Thalayasingam M, Gerez IF, Yap GC, Llanora GV, Chia IP, Chua L, et al. Clinical and immunochemical profiles of food challenge proven or anaphylactic shrimp allergy in tropical Singapore. Clin Exp Allergy. 2015; 45:687-97.

15. Lopata AL, Kleine-Tebbe J, Kamath SD. Allergens and molecular diagnostics of shellfish allergy: Part 22 of the Series Molecular Allergology. Allergo J Int. 2016;25:210-8.

16. Kumjim S, Jirapongsananuruk O, Piboonpocanun S. Cloning and characterization of recombinant tropomyosin of giant freshwater shrimp M. rosenbergii to determine major allergens causing allergic reactions among shrimp-allergic children. Asian Pac J Allergy Immunol. 2016;34: 229-35.

17. Piboonpocanun S, Jirapongsananuruk O, Tipayanon T, Boonchoo S, Goodman RE. Identification of hemocyanin as a novel non-cross-reactive allergen from the giant freshwater shrimp Macrobrachium rosenbergii. Mol Nutr Food Res. 2011;55:1492-8.

18. Sampson HA, Aceves S, Bock SA, James J, Jones S, Lang D, et al. Food allergy: a practice parameter update-2014. J Allergy Clin Immunol. 2014;134:1016-25 e43.

19. Burks AW, Tang M, Sicherer S, Muraro A, Eigenmann PA, Ebisawa M, et al. ICON: food allergy. J Allergy Clin Immunol. 2012;129:906-20.

20. Ho MH, Wong WH, Heine RG, Hosking CS, Hill DJ, Allen KJ. Early clinical predictors of remission of peanut allergy in children. J Allergy Clin Immunol. 2008;121:731-6.

21. Peters RL, Allen KJ, Dharmage SC, Koplin JJ, Dang T, Tilbrook KP, et al. Natural history of peanut allergy and predictors of resolution in the first 4 years of life: A population-based assessment. J Allergy Clin Immunol. 2015;135:1257-66 e1-2.

22. Bock SA, Sampson HA, Atkins FM, Zeiger RS, Lehrer S, Sachs M, et al. Double-blind, placebo-controlled food challenge (DBPCFC) as an office procedure: a manual. J Allergy Clin Immunol. 1988;82:986-97.

23. Nowak-Wegrzyn A, Assa'ad AH, Bahna SL, Bock SA, Sicherer SH, Teuber SS, et al. Work Group report: oral food challenge testing. J Allergy Clin Immunol. 2009;123:S365-83.

24. Sampson HA. Food allergy. Part 2: diagnosis and management. J Allergy Clin Immunol. 1999;103:981-9.

25. Sampson HA, Munoz-Furlong A, Campbell RL, Adkinson NF, Jr., Bock SA, Branum A, et al. Second symposium on the definition and management of anaphylaxis: summary report--Second National Institute of Allergy and Infectious Disease/Food Allergy and Anaphylaxis Network symposium. J Allergy Clin Immunol. 2006;117:391-7.

26. Daul CB, Morgan JE, Lehrer SB. The natural history of shrimp hypersensitivity. J Allergy Clin Immunol. 1990;86:88-93.

27. Ayuso R, Sanchez-Garcia S, Lin J, Fu Z, Ibanez MD, Carrillo T, et al Greater epitope recognition of shrimp allergens by children than by adults suggests that shrimp sensitization decreases with age. J Allergy Clin Immunol. 2010;125:1286-93.e3.

28. Kattan J. The Prevalence and Natural History of Food Allergy. Curr Allergy Asthma Rep. 2016;16:47. 
29. Savage J, Sicherer S, Wood R. The Natural History of Food Allergy. J Allergy Clin Immunol Pract. 2016;4:196-203; quiz 4.

30. Spergel JM. Natural history of cow's milk allergy. J Allergy Clin Immunol. 2013;131:813-4.

31. Boyano-Martinez T, Garcia-Ara C, Diaz-Pena JM, Martin-Esteban M. Prediction of tolerance on the basis of quantification of egg white-specific IgE antibodies in children with egg allergy. J Allergy Clin Immunol. 2002; 110:304-9.
32. Savage JH, Kaeding AJ, Matsui EC, Wood RA. The natural history of soy allergy. J Allergy Clin Immunol. 2010;125:683-6.

33. Keet CA, Matsui EC, Dhillon G, Lenehan P, Paterakis M, Wood RA. The natural history of wheat allergy. Ann Allergy Asthma Immunol. 2009; 102:410-5. 